\title{
Severe pulmonary hypertensive diseases: a perspective
}

\author{
N.F. Voelkel, R.M. Tuder
}

Severe pulmonary hypertensive diseases: a perspective. N.F. Voelkel, R.M. Tuder. CERS Journals Ltd 1999.

ABSTRACT: Clinically "severe pulmonary hypertension" is a group of diseases. The nomenclature of pulmonary hypertensive disorders is confusing since terms like "primary", "idiopathic", "unexplained" and "plexogenic" are often used interchangeably.

In this Point of view or perspective the authors challenge the validity of the traditional pathohistological classification as it had been provided by HEATH and EDWARDS [1]. A classification that is focused on histological and clinical association is proposed and a recommendation to reorder "Severe pulmonary hypertension" in an association-morphology-function context is provided.

The purpose of this "perspective" is to stimulate a discussion which hopefully will lead to a change in the presently used nomenclature and classification of pulmonary hypertensive disorders.

Eur Respir J 1999; 14: 1246-1250. Dept of Pathology, Pulmonary Hyper-
tension Center, University of Colorado Health Sciences Center, Denver, CO, USA

Correspondence: N.F. Voelkel, Pulmonary and Critical Care Medicine Division, University of Colorado Health Sciences Center, 4200 E. Ninth Avenue, C272 Denver, CO 80262, USA. Fax: 3033155632

Keywords: Plexiform arteriopathy, primary pulmonary hypertension, prostacyclin, pulmonary hypertension classification, vasodilator treatment, veno-occlusive disease

Received: November 231998

Accepted after revision September 61999
The term "primary" or "idiopathic" pulmonary hypertension $(\mathrm{PH})$ has been used to contrast a disease of unknown aetiology with pulmonary vascular disease (or diseases) that are associated with an identifiable cause. However, it is becoming increasingly clear that the presently used terminology of PH is no longer useful. Terms like "idiopathic," "primary" and "unexplained" PH are still being used and confuse patients, insurance carriers and often times physicians. More than 40 yrs ago, there was an attempt by pathologists to categorize the histopathological findings of pulmonary vascular disease [1], the term "unexplained plexogenic pulmonary arteriopathy" [2] was coined, yet described only one of the histological features of pulmonary vascular disease. Subsequently, WAGENVOORT [3] promoted the idea that a lung biopsy was necessary to establish the diagnosis of primary pulmonary hypertension $(\mathrm{PPH})$. However, with the introduction of effective therapy aimed at pulmonary vasoconstriction and blood vessel remodelling, such as calcium channel blockers [4, 5] and prostacyclin [6, 7], clinicians realized that the assessment of the vascular reactivity of a given patient serving as a "functional biopsy" is of some prognostic value and provides guidance for therapy. In contrast, knowledge of the lung pathology presently appears to be of lesser clinical usefulness.

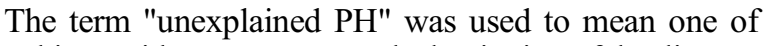
two things: either severe PH at the beginning of the diagnostic work-up without identification of a clear cause for secondary PH; or after all causes for secondary PH had been ruled out "unexplained" meant "idiopathic" and thus PPH.

As stated, the above mentioned terms are presently being used interchangeably and there continues to be confusion regarding the histopathological alterations of the pulmonary arteries that have been accepted to represent PPH. Traditionally, the three distinct histopathological forms of severe PH: 1) plexogenic or plexiform arteriopathy; 2) pulmonary veno-occlusive disease; and 3) pulmonary alveolar haemangiomatosis were all considered to be forms of PPH, yet they occur with very different frequencies and may very well be three different diseases.

Another point of confusion is the use of the word "primary". For example, although it is clear that anorexigen use can cause severe pulmonary vascular disease [8] identical in any and every aspect to the so-called PPH [9, 10] different investigators use different terms, either "anorexigen-induced PPH" or "severe PH associated with the use of anorexigens".

Lastly, the now widely accepted and very successful therapy of PPH with continuous infusion of prostacyclin $[6,7]$ has led to small therapeutic trials of continuous prostacyclin infusion in patients with severe $\mathrm{PH}$ associated with collagen vascular diseases [11], intracardiac shunts (R. Barst, Columbia-Presbyterian Medical Center, New York, USA; personal communication), human immunodeficiency virus (HIV)-related severe PH (G. Simonneau, Hospital Antoine-Beclere, Clamart, France; personal communication) and severe $\mathrm{PH}$ associated with portal hypertension [12]. Thus, if several forms of severe PH may respond to this treatment modality then an insistence on a sharp distinction between "primary" and severe PH associated with anorexigen use or with portal hypertension (the diagnosis of PPH being based on exclusion of all known causes) may not be of everyday clinical importance and perhaps may deny some patients effective treatment.

\section{Recommendation for a departure from the Heath and Edwards classification}

Prior histopathological classifications of severe PH assumed that the underlying alterations of the structure of the pulmonary arteries resulted either from increased pulmonary artery pressures (as postulated by HEATH and EDWARDS [1]) or vasoconstriction [13]. As one result of this "physiological" paradigm, the critically important altera- 
tions of the pulmonary vasculature in severe $\mathrm{PH}$ were felt to fundamentally involve the medial smooth muscle cells. Lesions of the intima, including the plexiform lesions were considered to represent the result of prolonged high pulmonary artery pressures or alternatively the result of fibrinoid necrosis [13]. These lesions were considered to be endstage lesions. The classification of HEATH and EDWARDS classification [1] was based on the authors' concept of progressive changes of the vascular alterations in $\mathrm{PH}$. According to this classification, the pulmonary vascular remodelling starts with medial hypertrophy, progresses through a stage of cellular intimal proliferation and fibrosis, followed by plexiform lesions, vascular dilation lesions and necrotizing arteritis. However, it is still unresolved today whether this progression actually occurs and if so relates to the duration of the disease or the degree of the PH. In addition, it must not be forgotten that the original paper by HEATH and EDWARDS [1] was based on the investigation of 67 cases of $\mathrm{PH}$ related to congenital cardiac shunt abnormalities, and that only two of their 67 cases were patients with PPH [1]. Clearly, by including these PPH cases, HEATH and Edwards [1] assumed that the pathobiology of PPH was similar to that in patients with secondary $\mathrm{PH}$.

The authors believe that critical reassessment of the classification of HEATH and EDWARDS [1], as it pertains to $\mathrm{PPH}$, is long overdue. Superficially, so-called PPH and disorders with left-to-right heart shunts may produce similar morphological alterations of the pulmonary circulation. However, in PH associated with left-to-right shunt, one of the factors responsible for vascular remodelling is probably the increased blood flow and the resulting phenotypic alterations of vascular cells caused by increased shear stress [14]. There is no evidence that a similar mechanism (i.e. flow mediated shear stress) initiates the cellular events in "PPH".

Given that pulmonary vascular remodelling includes both vascular smooth muscle cells (VSMC) and endothelial cell abnormalities, the authors believe that what is fundamentally altered in vascular remodelling is the VSMC-endothelial interaction. Although separated by the internal elastic lamina, VSMC and endothelial cells form essentially a syncytium. This syncytium responds to haemodynamic stress with an adaptive response that is teleologically appropriate. It makes "sense" for the haemodynamically stressed pulmonary vessel to fortify its wall. This normal, adaptive response is characterized by longitudinal extension of the smooth muscle cells and by smooth muscle cell hypertrophy. How the increase of pressure, vessel wall tension and shear stress are sensed by the endothelial cells and translated into this adaptive response is not understood. The authors can surmise that VSMC migration and perhaps pericyte differentiation occur in response to a combination of haemodynamic stress, hypoxia and inflammatory stimuli.

Medial hypertrophy occurs indiscriminately in all forms of mild or severe $\mathrm{PH}$, both in reversible and in irreversible forms of PH. The classification of HEATH and EDwards [1] of severe $\mathrm{PH}$, devised in 1958, was based solely on the analysis of haematoxylin and eosin stained slides and implied, as already stated, a sequence of morphological events in PH, which always starts with medial hypertrophy and subintimal changes. According to the classification, if medial hypertrophy is not readily apparent, there is no need to search for endothelial cell alterations, and therefore, it is not a case of PH! This is clearly not so [15].

There is growing evidence for a strong genetic influence in PPH, both at the level of genetic inheritance $[16,17]$ and the possible presence of somatic mutations that confer a growth advantage during the clonal expansion of pulmonary endothelial cells $[10,18]$. In contrast, there is currently no clear concept that links the medial hypertrophy or the subintimal changes pathogenetically to the socalled "advanced" or "terminal" vascular lesions (HeATH and EDWARDS [1] grades 4 through 6).

It is proposed that severe, sporadic $\mathrm{PH}$ and some forms of severe PH (such as associated with HIV infection, liver cirrhosis or the calcinosis, Raynaud's phenomenon, oesophageal involvement, sclerodactyly, and telangiectasia (CREST) syndrome) involve alterations of all vascular cells (endothelial cell, smooth muscle cells and fibroblast) and that the alterations are not necessarily or only related to alterations of pulmonary artery pressures or pulmonary artery flow. Perhaps extravascular factors also play a role. It is the authors' hypothesis that endothelial cell dysfunction is at the centre of the mechanisms that account for the development of severe pulmonary hypertension and that abnormal growth of endothelial cells within the pulmonary arteries is important in the pathobiology of severe PH. It is believed that medial and subintimal smooth muscle cell alterations and pulmonary endothelial cell growth and dysfunction are all present from the beginning of the disease.

Three-dimensional reconstruction studies indicate that endothelial cell proliferation, mostly in the form of plexiform abnormalities, occurs in the area of vascular bifurcations and further that plexiform lesions occur always proximal and concentric intima fibrotic lesions occur distal to the plexiform lesions [15]. It appears that the pathohistological findings allow a grouping of pulmonary vascular diseases based on the presence or absence of endothelial cell proliferation.

The authors recommend that the classification of HEATH and EDWARDS [1] should not be used any longer and that it should be replaced by an aetiology-neutral description of the key vascular abnormalities. An example of such a new histopathological classification is presented in table 1 .

Table 1. - A possible new histopathological classification of pulmonary hypertension

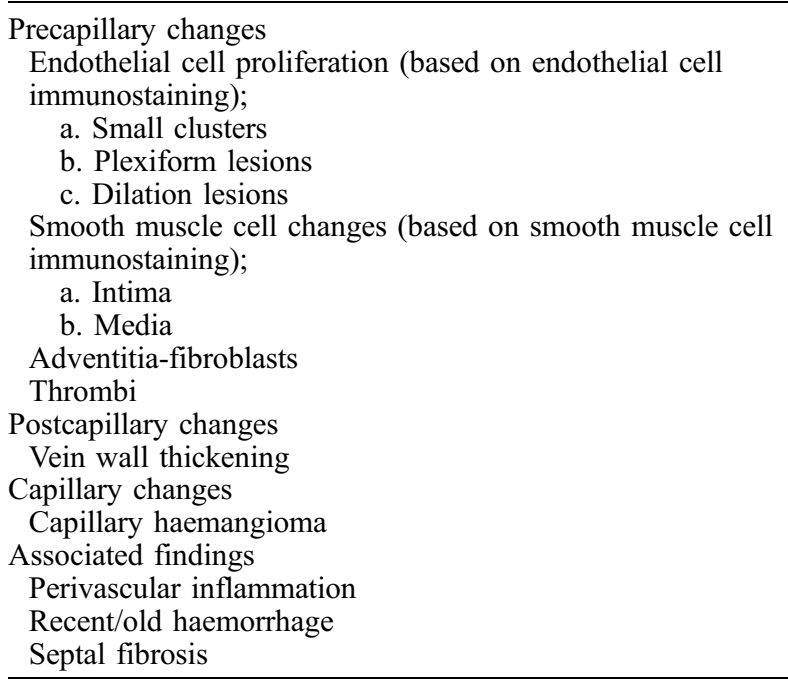




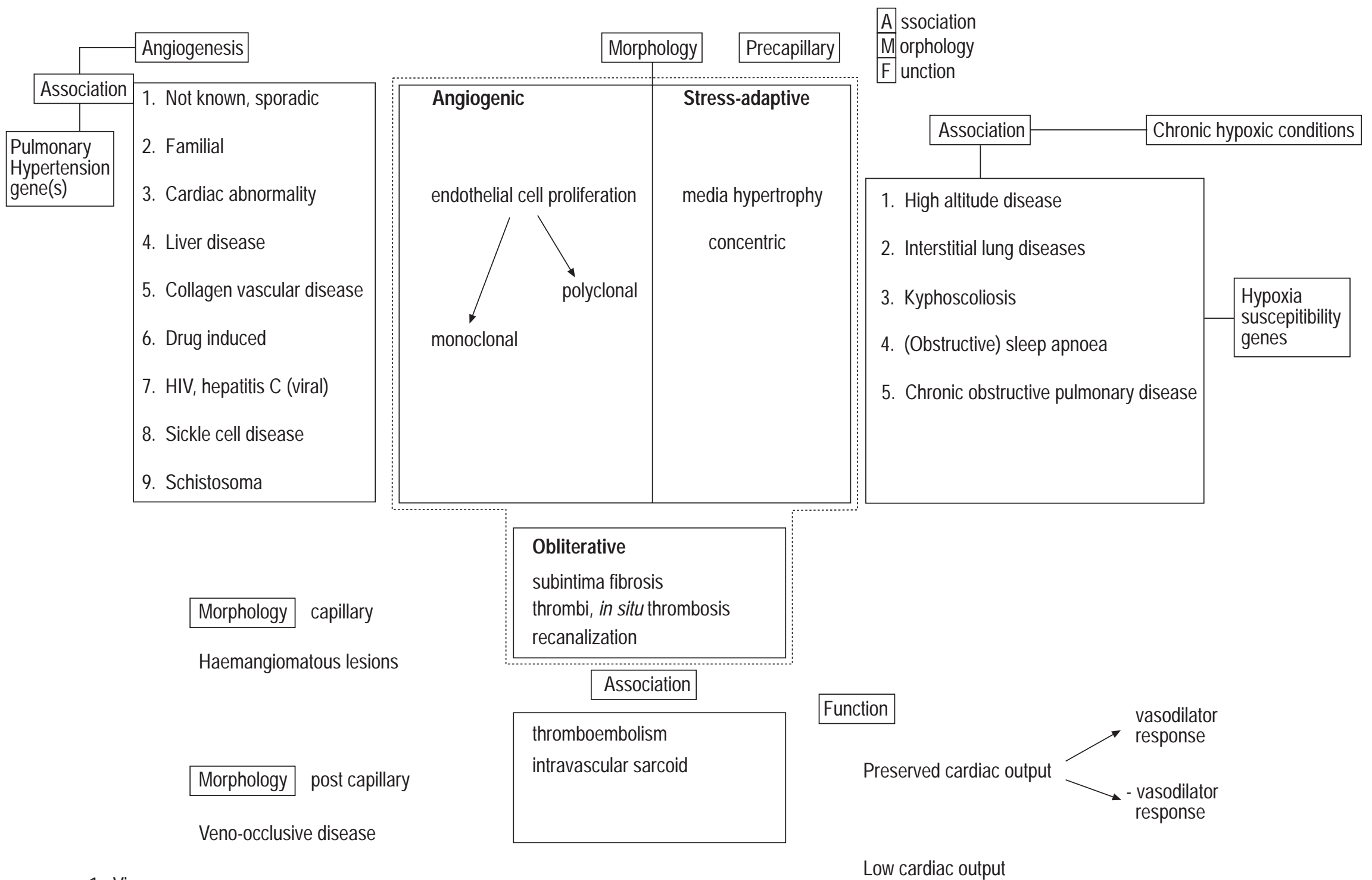

1. Virus

Low cardiac output

\section{Drugs}

Fig. 1. - Severe pulmonary hypertension: association, morphology, function (AMF) classification. A schematic that groups pulmonary vascular disease according to their dominant morphological features and sites, and according to their association with clinical and functional presentations. 


\section{Recommendation for a classification based on associated conditions}

In the following it is suggested that a new nomenclature that will be more flexible and devoid of terminology that continues to be confusing is considered.

The authors propose to eliminate the terms "primary," "idiopathic" and "secondary" PH. Instead, they propose the consideration of a classification that deals with all forms of severe $\mathrm{PH}$. The ordering principle of this classification could be based on known associations (A), the histopathological features (morphology) (M), and the functional assessment of the patient at the time of diagnosis (F). This new classification should allow a degree of flexibility and should be able to accommodate new pathobiological insights, new treatment strategies and allow the assessment of outcomes.

An example for a classification that is based on shared key morphological criteria, the site of the vessel lesions (precapillary or postcapillary), the known associated medical conditions and on the functional status of the patient is presented below. (fig. 1) The authors propose to separate groups of associations according to the historically described pathohistological findings. It is now clear that a pathologist cannot, after examination of the lung tissue sections, decide whether the tissue is from a patient with $\mathrm{HIV}$-associated $\mathrm{PH}$, a patient with anorexigen-induced $\mathrm{PH}$, a patient with $\mathrm{PH}$ and portal hypertension or a patient with familial PH $[19,20]$.

Alternatively, lung diseases associated with hypoxaemia or syndromes characterized by disordered breathing and hypoxaemia can be grouped together because their prominent key histological feature is vascular media thickening, whereas endothelial cell proliferation is generally absent or not very prominent $[21,22]$.

Veno-occlusive disease is mostly a postcapillary problem and not characterized by endothelial cell proliferation, therefore, probably pathogenetically different from the group of endothelial cell proliferative manifestations.

The authors' proposed "Association-Morphology-Function" (AMF) classification would describe a patient (for example) as a patient with "severe $\mathrm{PH}$, associated with anorexigen use, who has a low cardiac output and no response to acute vasodilator treatment". Implied in this statement is that the histopathological picture in this case is very probably characterized by endothelial cell proliferation, plexiform lesions, media hypertrophy and perhaps in situ thrombosis. Implied also is that this patient has a grave prognosis and will probably require treatment with prostacyclin.

On the other hand, a patient with kyphoscoliosis-associated $\mathrm{PH}$ will have a preserved cardiac output and the $\mathrm{PH}$ will likely be reduced by oxygen treatment; the lung vascular remodelling in all likelihood is dominated by muscularization of precapillary arteries, in situ thrombosis may or may not be present.

Of pathobiological importance may be that patients with sporadic ("primary") PH with familial PH and with anorexigen-induced severe ("primary") $\mathrm{PH}$ demonstrate pulmonary endothelial cell proliferation which is monoclonal, whereas this is not the case in patients with plexiform lesions and congenital intracardiac shunts or $\mathrm{PH}$ associated with the CREST syndrome [18].
The authors also propose that there is one set of genetic susceptibilities that facilitates the development of endothelial cell proliferative disorders and a different set of genes that is involved in the hypoxia-associated pulmonary vascular remodelling.

The response of a given patient with severe $\mathrm{PH}$ to acute vasodilator treatment is critically important because patients that show a clear haemodynamic response to acute prostacyclin $[23,24]$, adenosine [25] or inhaled NO [26] tend to respond, at least initially, to treatment with calcium antagonists [27].

With this perspective the authors wish to stimulate a discussion which hopefully will lead to a change of the presently used nomenclature and classification of pulmonary hypertensive disorders. The proposed AMF classification emphasizes the reordering of precapillary forms of PH. Certainly, other classifications could be proposed.

In conclusion, it makes a difference how pulmonary vascular diseases are named, generally, actions follow words. Many patients with severe, unreactive pulmonary hypertension may be treated in the future in the fashion in which patients with so-called primary pulmonary hypertension are currently treated.

\section{References}

1. Heath D, Edwards JE. The pathology of pulmonary hypertensive disease. A description of six grades of structural changes in the pulmonary arteries with special reference to congenital cardiac septal changes. Circulation 1958; 18: 533.

2. Primary Pulmonary Hypertension: report on a WHO Meeting. Hatano S, Strasser T, eds. Geneva; World Health Organization, 1975.

3. Wagenvoort CA. Lung biopsy specimens in the evaluation of pulmonary vascular disease. Chest 1980; 77 : 614-625.

4. Rich S, Brundage BH. High-dose calcium channelblocking therapy for primary pulmonary hypertension: evidence for long-term reduction in pulmonary arterial pressure and regression of right ventricular hypertrophy. Circulation 1987; 76: 135-141.

5. Rich S, Kaufmann E, Levy PS. The effect of high doses of calcium-channel blockers on survival in primary pulmonary hypertension. $N$ Engl J Med 1992; 327: 76-81.

6. Jones DK, Higenbottam TW, Wallwork J. Treatment of primary pulmonary hypertension with intravenous epoprostenol (prostacyclin). Br Heart J 1987; 57: 270-278.

7. Barst RJ, Rubin LJ, Long WA, et al. A comparison of continuous intravenous epoprostenol (prostacyclin) with conventional therapy for primary pulmonary hypertension. N Engl J Med 1996; 334: 296-301.

8. Abenhaim L, Moride Y, Brenot F, et al. Appetitesuppressant drugs and the risk of primary pulmonary hypertension. N Engl J Med 1996; 335: 609-616.

9. Mark EJ, Patalas ED, Change HT, Evans RJ, Kessler SC. Fatal pulmonary hypertension associated with short-term use of fenfluramine and phentermine. N Engl J Med 1997; 337: 602-605.

10. Tuder RM, Radisavljevic Z, Shroyer KR, Polak JM, Voelkel NF. Monoclonal endothelial cells in appetite suppressant-associated pulmonary hypertension. Am J Respir Crit Care Med 1998; 158: 1999-2001.

11. Humbert M, Sanchez O, Fartoukh M, Jagot JL, Sitbon O, Simonneau G. Treatment of severe pulmonary hypertension secondary to connective tissue disease with 
continuous IV epoprostenol (prostacyclin). Chest 1998; 114: $80 \mathrm{~S}-82 \mathrm{~S}$.

12. Kuo PC, Plotkin JS, Howell CD, Bartlett ST, Rubin LJ. Continuous infusion of epoprostenol for the treatment of portopulmonary hypertension. Transplantation 1997; 63: 604-606.

13. Wagenvoort CA, Wagenvoort N. Pathology of Pulmonary Hypertension. New York, John Wiley and Sons, 1977.

14. Gimbrone MAJ, Nagel T, Topper JN. Biomechanical activation: an emerging paradigm in endothelial adhesion biology. J Clin Invest 1997; 100: S61-S65.

15. Cool CD, Steward JC, Werahera P, et al. Three-dimensional reconstruction of pulmonary arteries in plexiform pulmonary hypertension using cell-specific markers: evidence for a dynamic and heterogeneous process of pulmonary endothelial cell growth. Am J Path 1999; 155: 411-419.

16. Nichols WC, Killer DL, Slovis B, et al. Localization of the gene for familial primary pulmonary hypertension to chromosome 2q31-32. Nat Genet 1997; 15: 277-280.

17. Morse JH, Jones AC, Barst RJ, et al. Mapping of familial primary pulmonary hypertension locus (PPH1) to chromosome 2q31-q32. Circulation 1997; 95: 2603-2606.

18. Lee SD, Shroyer Kr, Markham NE, Cool CD, Voelkel NF, Tuder RM. Monoclonal endothelial cell proliferation is present in primary but not secondary pulmonary hypertension. J Clin Invest 1998; 101: 927-934.

19. Cool CD, Tuder RM, Voelkel NF. Plexiform pulmonary vascular lesions in scleroderma and AIDS: is there a common pathogenesis? Hum Pathol 1997; 28: 434442.

20. Cool CD, Voelkel NF, Wheeler LJ, Tuder RM. Analysis of vascular lesions in familial primary pulmonary hypertension (FPPH): insights into the endothelial cell as the common denominator of a morphologically heterogeneous disorder. Am J Resp Crit Care Med 1997; 155: A628.

21. Tuder RM, Cool CD, Jennings C, Voelkel NF. Pulmonary vascular involvement in interstitial lung disease. In: Schwartz SM, King TEJ, eds. Interstitial Lung Disease. 3rd Edn. Hamilton, Ontario, Canada, BC Decker, 1998; pp. 251-263.

22. Tuder RM, Groves GM, Badesch DB, Voelkel NF. Exuberant endothelial cell growth and elements of inflammation are present in plexiform lesions of pulmonary hypertension. Am J Pathol 1994; 144: 275-285.

23. Groves BM, Badesch DB, Turkevich D, et al. Correlation of acute prostacyclin response in primary (unexplained) pulmonary hypertension with efficacy of treatment with calcium channel blockers and survival. In: Weir EK, Hume JR, Reeves JT, eds. Ion Flux in Pulmonary Vascular Control. New York, Plenum Publishing, 1993; pp. 317-330.

24. Raffy O, Azarian R, Brenot F, et al. Clinical significance of the pulmonary vasodilator response during short-term testing with prostacyclin in primary pulmonary hypertension. Circulation 1996; 93: 484-488.

25. Mclaughlin VV, Genthner DE, Panella MM, Rich S. Reduction in pulmonary vascular resistance with longterm epoprostenol (prostacyclin) therapy in primary pulmonary hypertension. N Engl J Med 1998; 338: 273-277.

26. Pepke-Zaba J, Higenbottam TW, Dinh-Xuan AT, Stone D, Wallwork J. Inhaled nitric oxide as a cause of selective pulmonary vasodilation in pulmonary hypertension. Lancet 1991; 338: 1173-1174.

27. Sitbon O, Humbert M, Jagot JL, et al. Inhaled nitric oxide as a screening agent for safely identifying responders to oral calcium-channel blockers in primary pulmonary hypertension. Eur Respir J 1998; 12: 265-270. 